\title{
40 Years of Technical Teacher Training in Hungary
}

\author{
http://dx.doi.org/10.3991/ijep.v3iS2.2459 \\ Agnes Toth, Pal Pentelenyi \\ Óbuda University, Budapest, Hungary
}

\begin{abstract}
The study outlines the significant periods of technical teacher training in Hungary embedded in the harmonization process of the European diversity.
\end{abstract}

Index Terms-vocational training, teacher competencies and roles, Master level teacher of engineering, Bologna process, training reforms

\section{INTRODUCTION}

Recently a new wave of reforms reached teacher training in Hungary when it is necessary to examine the situation of technical teacher training as well.

We would like to present an overview of three periods. The first one started in the seventies and ended when higher education institutions introduced the principles of the Bologna system across Europe. The second period covers the Bologna scheme technical teacher training. At last a third period will be forecasted, which will start as soon as the new regulations will have been approved by the Hungarian government.

\section{BEFORE THE BOLOGNA SYSTEM REFORMS}

In parallel to the extension of technical secondary schools and because of the sudden need for technical teachers several higher educational institutions introduced technical teacher training in 1972:

- Technical University of Budapest

- Budapest Polytechnic (now Óbuda University)

- University of Debrecen

- Dunaújváros Technical College

- Kecskemét Technical College

- University of Pécs

- Széchenyi István University (Győr)

- University of West Hungary

Out of the listed Hungarian institutions only two had master level engineering courses, all the others paired teacher training to BEng level engineering courses.

The duration of the technical teacher training course was 2 additional semesters (60 credits) added to the engineering course in full time training. It altogether extended to 8 semesters when paired with any type of BSc level engineering.

Students of the technical teacher training course studied pedagogical and methodological subject-matters in parallel to their engineering training. With their degree in technical education they were entitled to teach either at technical secondary schools and apprentice schools or in industrial training and retraining.

If they decided to work as engineers they could utilise their pedagogical and psychological background when working in teams or co-operating with other partners.

The chances of technical teachers to find employment in the labour market were enhanced by the fact that they received two separate degrees (BEng and BEd or MEng and MEd) having completed their studies in both courses.

It was a general rule in the Hungarian teacher training regulation that the completion of teacher training courses has not modified the level of the basic (e.g. engineering) course as it is shown in the above examples.

\section{CONCLUSIONS BASED ON EUROPEAN COMPARATIVE STUDIES}

A former president of ATEE (Association for Teacher Education in Europe) Anne-Lise Hostmark Tarrou (Norway) published the first comparative study of vocational teacher training in 1989 [1].

Encouraged by the ATEE Working Group for Technical and Vocational Teacher Training =WG 3 and supported by TEMPUS a thorough analysis has been prepared in 1994 [2].

The structure and the content of nine European technical teacher training systems were analyzed in this study. Austria, Finland, France, Germany, Italy, Holland, Hungary, Norway and the United Kingdom had been chosen for the comparative analysis. The purpose for choosing the countries to be examined was to demonstrate the various main types of technical teacher training.

This study dealt with the structure, length and levels of technical teacher training beside the investigation of paired technical training (size of sets and coherence of technical subjects). The content and principles of the pedagogical module (including practice) were also examined [3].

\section{A. Structure, length and levels}

When we examine the structure of technical teacher training we consider the relation of technical and pedagogical items.

In the parallel or concurrent model, technical and pedagogical training run parallel to each other either during the entire training or over a longer period of the training. Differences can be seen regarding the starting point of the pedagogical module within the entire training. The sooner the preparation starts for the educational profession the greater the opportunities are for gaining educational experience gradually, for increasing motivation towards 
teaching career and for the efficient structuring of the pedagogical training content. Parallel training systems had been realised in Holland, France and Hungary.

In the consecutive training system, pedagogical training starts after the completion of technical training. Although this model does not have the advantages of the parallel system it is widely used because of its economical nature and simple organisation. It is mainly provided for later career modifications. This type of training was organised in the United Kingdom where the consecutive training system is preferred.

The length of study varied a great deal in these forms from as little as 4 weeks to as long as 6 and $1 / 2$ years.

The total number of contact hours regarding the pedagogical module was the smallest (150 hours) in Italian training, and the longest (41 weeks) in Dutch training.

Levels were created on one hand, by grading the engineering training, on the other hand, by grading the pedagogical training. In a sense, grading in itself created special forms for continuing education.

If the engineering part of the training was more or less equivalent to the engineering training, the engineering qualification of technical teachers could be: BEng., MEng. or Ing., Dipl.-Ing. (e.g. in the United Kingdom, Hungary and Austria).

Pedagogical qualifications were earned according to the duration of technical teacher studies in France and in the United Kingdom where these qualifications formed a ladder, making it possible to leave the training with a relevant qualification at different levels. It is quite easy to notice the influence of this principle in the Bologna system of higher education.

\section{B. Framework of technical training}

The examination of the engineering module - as one of the two main modules of technical teacher training deserves special attention from the stand-point of training objectives and continuing education.

The content of any engineering subject must be taught in relation to other subject elements if the whole of the subject is to be understood (e.g. mechanical components can not be taught without mechanics, machines without fluid dynamics, electronics without the basics of electrical engineering etc.).

The connections among subject areas multiply when solving problems [5]. Even a simple design problem requires knowledge of engineering materials, as well as production engineering.

The system of engineering knowledge is defined by the engineering activity which is outlined in the training objectives. Arbitrarily separated sets of engineering knowledge do not form coherent knowledge, therefore they can not comprise the content of the engineering module in technical teacher training.

In some countries (e.g. Germany and France) the amount of engineering knowledge was smaller, and a general subject was paired with an engineering subject area (e.g. in Germany).

In other countries (e.g. Holland and Hungary) the proportions of technical teacher training made it possible to form a coherent content of engineering training within teacher training. The engineering training of would-be technical teachers and engineers were equivalent in some countries (e.g. Austria and Italy) at MEng level and in many other countries at BEng or both levels as well.

This is important not only because the training is more economical but also because the engineering subjects form a coherent system. Teachers of a certain engineering field (e.g. mechanical, electrical, etc.) may teach 10-15 different technical subjects during their career.

By having wider engineering knowledge they can adapt themselves to the specialization of technical secondary schools without difficulties and they can also accept changes in the content of subject areas more easily.

This issue includes the problem of whether the qualification of technical teachers should comprise a qualification for a certain technical field as well. This means that if the graduates are to be able to get jobs in industry for a period of time, they must have a qualification and, consequently, training which is very similar, or even equal, to regular technical training.

The proportion of the engineering module within the total training was above $90 \%$ in Austria and Italy, it was $75 \%$ in the U.K. and Hungary at BEng level, $66 \%$ in Holland, ca $60 \%$ in France and ca 50\% in Germany.

Should the future technical teachers have experiences of technical practice?

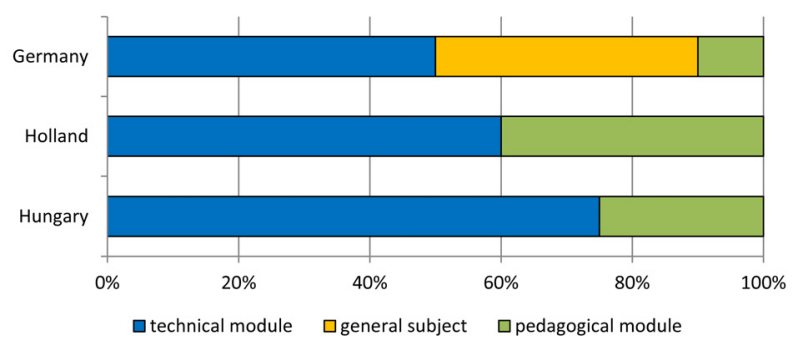

Figure 1. Proportions of the main modules in parallel technical teacher training

This is important because

- would-be teachers can gain practice (teaching in practical fields is unimaginable without practice)

- these practical periods can be repeated from time to time if changes in technology make it necessary

- those graduates who do not get work as teachers can easily find a job and their psychological and educational knowledge will help them in their advancement

- those teachers who prove to be unsuited to teaching once they have begun their teaching career can find a job without retraining.

All these reasons support the idea that technical teachers should have a technical qualification beside their teaching qualification.

The importance of engineering practice was indicated not only by the fact, that it provided opportunity for gaining engineering experience, but by the reality that it was also a precondition for being admitted to technical teacher training, as it was in Austria, Finland, Norway and the United Kingdom.

\section{Characteristics of the pedagogical module}

Although technical qualification (and practice) was a precondition of employment for technical education in 
many countries, the lack of pedagogical qualification was often ignored and could be obtained later in a form of inservice training (e.g. in Great-Britain, in Austria and in Italy).

Pedagogical practice was regulated by the curriculum during the training in most countries, or as a final part of the training (e.g. in Germany).

In Germany school practice extended to two years, this is why it could not be shown in the diagram below. The Dutch practice was planned with gradually growing tasks while in Finland teaching with full load was the central element of the process.

The Hungarian practice had been rather distorted with a great proportion of observation and a small portion of school teaching at that time.

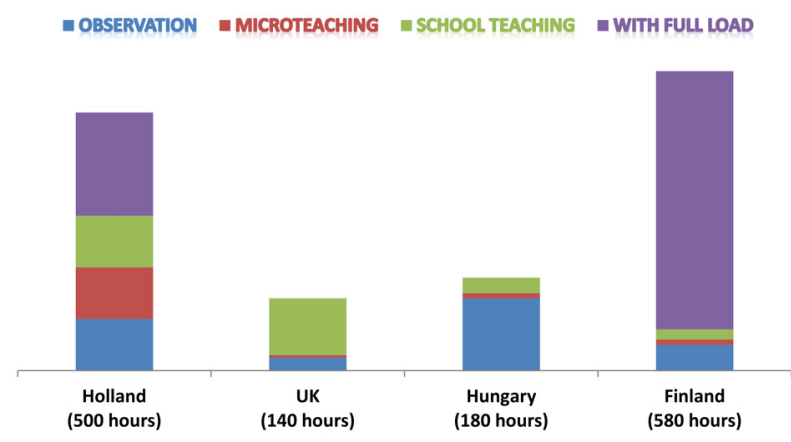

Figure 2. School practice

In some countries (in France and Austria) special attention was given to developing the personal values of teachers during training.

Practicing different educational roles was in the forefront in Great Britain and Holland. The educational roles were defined in the curriculum of these countries.

In Norway special education of pupils with learning disabilities was compulsory during initial teacher training.

In Eastern European countries a wide pedagogical culture was more predominant than preparation for a teaching profession. Where theory was strong (e.g. in Hungary) the argument that theory proves to be profitable in the long run was accepted.

\section{Conclusions for the future}

Five typical models are worth studying even now (after the Bologna type harmonization) if we wish to find the best solutions to the complexity of technical teacher training.

- Subject matter based theoretical pedagogical training (organized in parallel to the technical training) characterized technical teacher training in Holland [4].

- Competency based pedagogical training (organized mostly consecutively after the technical training) characterized the training in the United Kingdom [2].

- Students were qualified to teach engineering and a chosen general subject after a nine semester university training followed by a two year long practical training in Germany.

- Flexible training based on negotiations with the technical teacher training students according to their individual needs in Finland.
- In-service training when the students are already employed as teachers without the necessary pedagogical qualification. In this form theory and practice are taught in integrity. Austria provided a clear realization of this model with a unique initiative to determine the minimum requirements for technical teacher qualification worldwide. They had been introduced successfully (title of Ing. paed.-IGIP) [6].

\section{Changes and Consequences due to the Bologna PROCESS REFORMS}

The new type of training leading to the master level qualification for teacher of engineering was successfully accredited in Hungary at the end of 2006. The two year long Master level technical teacher training is built on a BSc qualification of engineering.

During the BSc level engineering training there is an opportunity for the students to get acquainted with educational studies by choosing from optional courses offered of this path. Basics of pedagogy, psychology, and communication are provided altogether for 10 credits with an emphasis of developing practical skills. This preparatory phase serves three goals: provide a kind of career guidance by showing a sample of teacher education; motivate potential students for pursuing educational studies; assist the teaching staff in the selection process to find the best students for master level engineering educational studies taking into consideration not only the achievements in engineering studies but also the affinity for the teaching profession.

When designing the content of this preparatory phase we had to consider goals and costs together. The third goal is to observe the applicants in smaller groups during their learning activities. At the same time it is a general requirement to form larger groups to have lower training costs.

There was a long debate on the question if passing the preparatory course should be obligatory for correspondence course students before being admitted to teacher training. In the end it was not required because their other values regarding engineering experiences were highly evaluated.

The master level phase of studies leading to the qualification for teacher of engineering consists of three elements: engineering (widening and deepening the students' technical knowledge), pedagogical-psychological (focusing on the teaching profession) and practical (teaching engineering during 14 weeks).

MA teacher of engineering course enables students to conduct theoretical, practical and laboratory work in the area of their specialised profile.

Graduates in technical teacher training are thought to have better opportunities to find employment in engineering jobs too. They could be in demand on account of their ability to communicate effectively as well as their sophisticated treatment of colleagues rooted in their qualifications in pedagogy and psychology. They can be readily employed in HR management roles and in a wide range of spheres of engineering.

Another type of pedagogical training is the BSc technical trainer course, which enables students to prepare for combining practical work with a theoretical profile in their specialist areas. They may provide training mostly in 
workshops of technical secondary or vocational schools, adult education and at engineering and manufacturing companies.

\section{BEYOND AND WITHIN THE BOLOGNA SYSTEM}

After five years of the two cycle teacher training practice the training institutions had to face several consequences.

Teacher training exclusively pursued in the second cycle decreased the number of students in all areas, but very painfully in the area of natural sciences. Non vocational schools preparing pupils for higher education could not recruit new staff members.

Furthermore, in general areas degrees gained after the first cycle could not be used in any employment, therefore completion of additional courses were needed.

The problem of technical teacher training is just the opposite. The BSc engineering degree is too much valuable in the labour market and the young engineers with the offer of relatively high salaries did not consider technical teacher training career. The opportunity for full time training could not be realized because of the lack of interest.

In the past five years technical teacher training could be implemented only in correspondence courses. Students were recruited from three types of professionals:

- students who previously gained BSc and BEd degrees and wanted to have a master degree,

- freshly graduated BSc students,

- teachers of technical secondary schools with BSc degree and often a long period of engineering practice but without pedagogical qualification

As the years passed, the first group was getting smaller, the second group was constantly a small one, while the third group was increasing.

In general it can be stated, that technical teacher training can not reach a high quality if it can be realized exclusively by correspondence training (as it was concluded in phase III.).

The new scheme intends to combine the beneficial features of the two previous systems. The future technical teacher training will provide MEd degree and can be run in the following ways:

- One cycle form making possible the enrolment of pupils having finished their secondary schools with their general certificate of education. The core of the training is envisaged to be run full time. For technical teacher training the length of studies will be 5 years (300 credits), which includes a one year practice in vocational schools supported by mentoring from the secondary school and tutoring (supervision) from the higher educational institution. Because of the substantial practical training the technical module of the training can not cover the entire content of the BSc engineering training. Therefore, in the future the BSc degree can be obtained by passing an additional engineering semester. All in all, the priority has changed in the new regulation and teacher training is placed to the centre.

- Two cycle form (for those applicants who want to have a teacher qualification after some years of engineering employment). This form is envisaged mainly as a form for correspondence courses when the students work beside their studies either as engineers or as teachers. It is an additional value of this form bringing engineering experience to the technical secondary schools. These professionals can create a fruitful cooperation with their young colleagues who are highly prepared from theory but otherwise "greenhorns", because their whole professional life was spent among the walls of the schools.

Both forms are going to preserve the value of double qualification for teachers of engineering.

Those teachers who have their Bachelor level qualification according to the regulations of teacher training before the Bologna system (having got their technical teacher degree after four years of study) may pursue 60 credit complementary studies of to obtain MEd degrees.

\section{Future CHALLENGES}

\section{A. Direct recruitment}

Due to the new decision, that technical teacher training can be realised in one cycle form, the students for full time courses have to be recruited directly from secondary school leavers.

Although at the very beginning of technical teacher training this method worked successfully, later on the stronger attraction of engineering courses lessened the interest for teacher training. A second recruitment solved the problem, because it was possible to offer teacher training for the students of engineering courses within the institution.

The revival of this pattern is possible but the methods have to be found out for the new circumstances. Because of a high level transparency the entrance procedures are unified and possibly the students of engineering courses have to "leave" their engineering course so that they could be enrolled into technical teacher training courses.

It is a challenge to find the ways how to motivate the students to bring this decision. The higher value of the master level qualification is an advantage. The longer period of the student status is in one sense pleasant but otherwise costly.

The BSc engineering qualification can be reached by a one term additional engineering complementary course. Altogether with 11 successful semesters one can receive a MEd and a BSc degree.

The aim of changing the order of the expected degrees is to lead the graduates towards the technical secondary schools.

\section{B. Curriculum development for one cycle technical teacher training}

It is a great challenge to find the best way to a high level professional and economic training at a large university.

The new regulation defines 12 qualifications for technical teachers:

Teacher of Engineering (Mechanical)

Teacher of Engineering (Electrical)

Teacher of Engineering (Information Technology)

Teacher of Engineering (Biochemical and Chemical) 


\section{YEARS OF TECHNICAL TEACHER TRAINING IN HUNGARY}

Teacher of Engineering (Civil and Architectural)

Teacher of Engineering (Light Industry)

Teacher of Engineering (Timber Industry)

Teacher of Engineering (Printing Industry)

Teacher of Engineering (Transportation)

Teacher of Engineering (Environmental Protection)

Teacher of Engineering (Civil and Safety)

Teacher of Engineering (Business Administration)

The Óbuda University has been accredited to run technical teacher training for 6 of them.

It is important to harmonize the pedagogical module for various specializations of technical teacher training. Without this harmonization the pedagogical training could be organized only for small groups (3-5 students) while with a full harmony the groups could have 25-30 students or more. Before the introduction of the Bologna system the university had 100-120 technical teacher training students per year, out of which 100 students had state support for their full time studies. The training costs can be greatly decreased by harmonizing the pedagogical training.

Moreover, the engineering training needs a greater level of harmonization because the pedagogical training covers only 100 credits out of total 300 credits. The greater part remains for the engineering training. 200 credit engineering curriculum has to be harmonized for 6 specializations at various faculties.

A thorough analysis of the engineering curriculum selected those items which can be offered two semesters later for technical teacher training students than for engineering students. These items are subjects of engineering specializations and subjects of economy, quality management, legal studies, etc. A gap gained this way can be used for pedagogical training.

On one hand the engineering subject matters are delivered together for engineering students and teacher training students. On the other hand pedagogical subject matters and practice are organized for all teacher training students simultaneously.

\section{Career model for teachers}

Great differences of financial expectations show a strong drawback for future students regarding engineering and educational employment. It is an already visible intention of the government to strengthen confidence in teachers' career with a reliable model.

\section{REFERENCES}

[1] Tarrou, A.H.(ed): Initial technical and vocational teacher education. ATEE WG3. 1989. 94 p.

[2] Toth, A.: Comparative analysis of technical teacher training systems.In: ATEE Cahier No. 9. Drukkerij Nijs-herent, Brussels, 1995. 39-52. p.

[3] Varga, L.: Comparative study on the theoretical training of technical teachers. In: ATEE Cahier No 9. Drukkerij Nijs-herent, Brussels, 1995. 53-64. p.

[4] Oddens, D.A.M.: A systematic approach to teaching technical subjects. In: ATEE Cahier No. 9. Drukkerij Nijs-herent, Brussels, 1995. 78-88. p.

[5] Dreyfus, A.: Selecting appropriate strategies for laboratory teaching. A problem in teacher training. European Journal of Teacher Education 16 (3) 1993. http://dx.doi.org/10.1080/02 $\underline{61976930160307}$

[6] Melezinek, A.: Ingeneurspädagogik. Grundlagen einer Didaktik des Technik-Unterrichtes. Wien/New York. 1977.

\section{AUTHORS}

Agnes Toth and Pal Pentelenyi are with the Trefort Ágoston Centre for Engineering Education, Óbuda University, Budapest, Hungary (toth.belane@tmpk.uniobuda.hu, pentelenyi.pal@tmpk.uni-obuda.hu)

This article is an extended and modified version of a paper presented at the International Conference on Engineering Pedagogy (IGIP2012), held 26 - 28 September 2012, in Villach, Austria. Received18 december 2012. Published as resubmitted by the authors 27 February 2013. 